\title{
Lusioersily
}

\section{3-D vertically aligned few layer graphene-partially reduced graphene oxide/sulfur electrodes for high performance lithium-sulfur batteries}

Singh, D. P., Soin, N., Sharma, S., Basak, S., Sachdeva, S., Roy, S. S., Zanderbergen, H. W., McLaughlin, J. A., Huijben, M., \& Wagemaker, M. (2017). 3-D vertically aligned few layer graphene-partially reduced graphene oxide/sulfur electrodes for high performance lithium-sulfur batteries. Sustainable Energy and Fuels, 1(7), 15161523. https://doi.org/10.1039/C7SE00195A

Link to publication record in Ulster University Research Portal

Published in:

Sustainable Energy and Fuels

Publication Status:

Published (in print/issue): 13/07/2017

DOI:

10.1039/C7SE00195A

Document Version

Publisher's PDF, also known as Version of record

\section{General rights}

Copyright for the publications made accessible via Ulster University's Research Portal is retained by the author(s) and / or other copyright owners and it is a condition of accessing these publications that users recognise and abide by the legal requirements associated with these rights.

\section{Take down policy}

The Research Portal is Ulster University's institutional repository that provides access to Ulster's research outputs. Every effort has been made to ensure that content in the Research Portal does not infringe any person's rights, or applicable UK laws. If you discover content in the Research Portal that you believe breaches copyright or violates any law, please contact pure-support@ulster.ac.uk. 


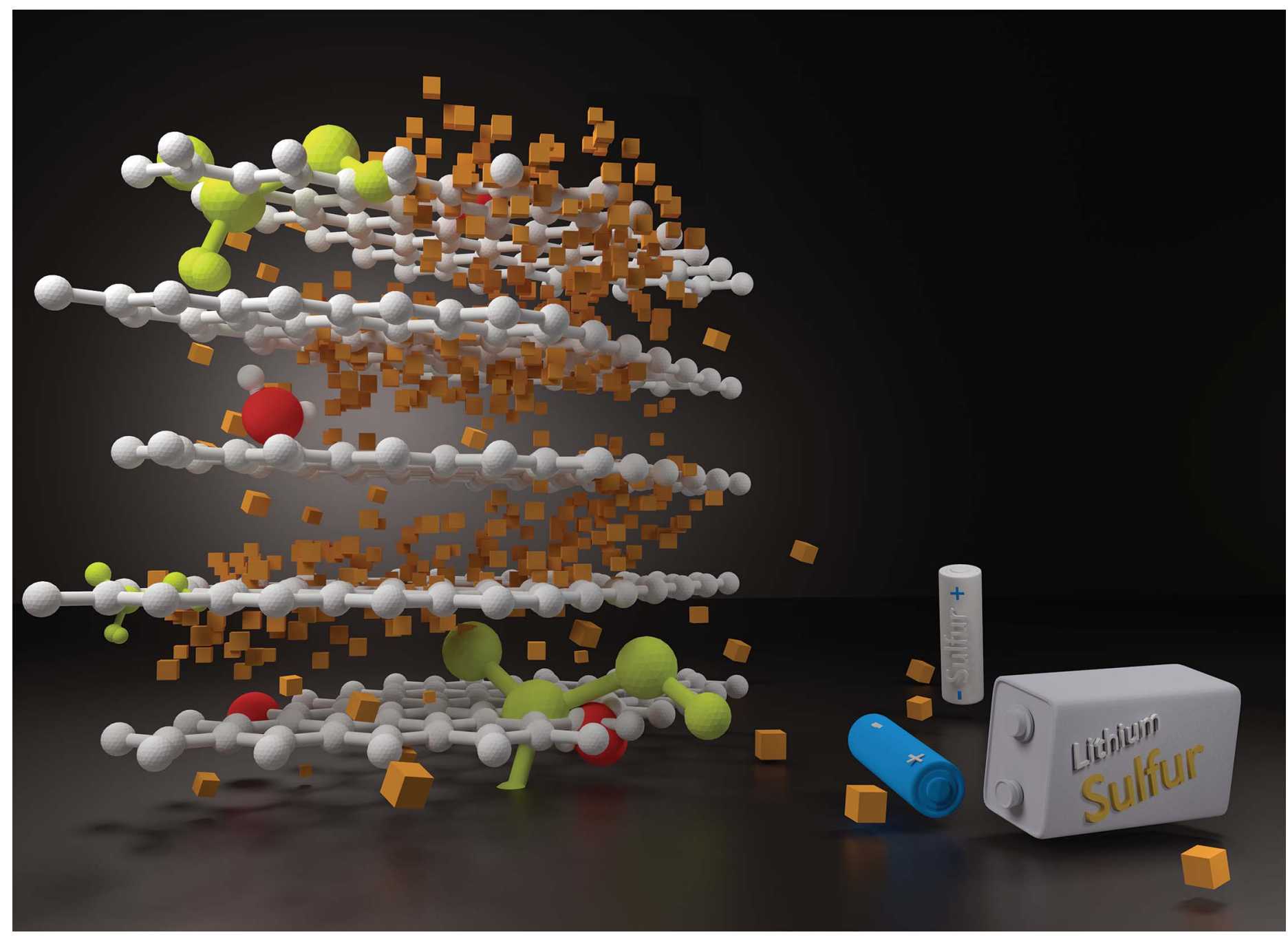

Showcasing collaborative research from the Delft University of Technology, University of Bolton, University of Birmingham and the University of Ulster.

3-D vertically aligned few layer graphene - partially reduced graphene oxide/sulfur electrodes for high performance lithium-sulfur batteries

Multifunctional nanocomposites with a judicious balance of surface oxygen functional groups and 3-D nano-architecture facilitate electronic and ionic transport, and ease of electrolyte accessibility. The confinement of the polysulfide shuttles within the nanocomposite 3-D matrix leads to excellent capacity and cycling capabilities.

\section{As featured in:}

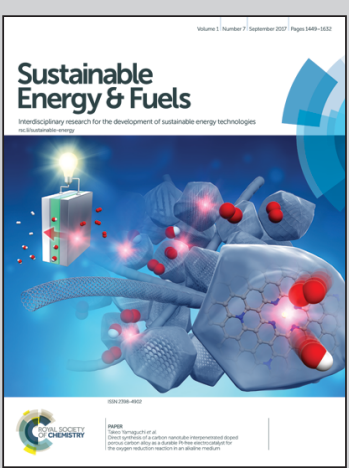

See D. P. Singh, N. Soin et al., Sustainable Energy Fuels, 2017, 1, 1516. 


\section{COMMUNICATION}

Check for updates

Cite this: Sustainable Energy Fuels, 2017, 1, 1516

Received 11th April 2017 Accepted 7th July 2017

DOI: $10.1039 / \mathrm{c} 7 \mathrm{se} 00195 \mathrm{a}$

rsc.li/sustainable-energy

\section{3-D vertically aligned few layer graphene - partially reduced graphene oxide/sulfur electrodes for high performance lithium-sulfur batteries $\dagger$}

\author{
D. P. Singh, ${ }^{\star a b}$ N. Soin, (DD ${ }^{* c d}$ S. Sharma, ${ }^{e}$ S. Basak, ${ }^{f}$ S. Sachdeva, (D) ${ }^{a}$ S. S. Roy, ${ }^{g}$ \\ H. W. Zanderbergen, ${ }^{f}$ J. A. McLaughlin, ${ }^{d}$ M. Huijben ${ }^{b}$ and M. Wagemaker ${ }^{a}$
}

3-D vertically aligned few-layered graphene (FLGs) nanoflakes synthesised using microwave plasma enhanced chemical vapour deposition are melt-impregnated with partially reduced graphene oxidesulfur (PrGO-S) nanocomposites for use in lithium-sulfur batteries. The aligned structure and the presence of interconnected micro voids/channels in the 3-D FLG/PrGO-S electrodes serves as template not only for the high sulfur loading (up to $80 \mathrm{wt} \%$, areal loading of $1.2 \mathrm{mg} \mathrm{cm}^{-2}$ ) but also compensates for the volume changes occurring during charge-discharge cycles. The inter-connectivity of the electrode system further facilitates fast electronic and ionic transport pathways. Consequently, the binder-free 3-D FLG/PrGO-S electrodes display a high first-cycle capacity ( $1320 \mathrm{~mA} \mathrm{~h} \mathrm{~g}^{-1}$ at C/20), along with excellent rate capability of $\sim 830 \mathrm{~mA} \mathrm{~h} \mathrm{~g}^{-1}$ and $700 \mathrm{~mA} \mathrm{~h} \mathrm{~g}^{-1}$ at $2 \mathrm{C}$ and $5 \mathrm{C}$ rates, respectively. The residual functional groups of $\operatorname{PrGO}(-\mathrm{OH}$, $-\mathrm{C}-\mathrm{O}-\mathrm{C}-$ and $-\mathrm{COOH}$ ) facilitate fast and reversible capture of $\mathrm{Li}^{+}$ ions while confining the polysulfide shuttles, thus, contributing to excellent cycling capability and retention capacity. The 3D electrodes demonstrate excellent capacity retention of $\sim 80 \%\left(1040 \mathrm{~mA} \mathrm{~h} \mathrm{~g}^{-1}\right.$ at $\mathrm{C} / 10$ ) over 350 charge-discharge cycles. Comparatively, the 2-D planar PrGO-S electrodes displayed poor electronic conductivity and can only provide $560 \mathrm{~mA} \mathrm{~h} \mathrm{~g}{ }^{-1}$ after 150 cycles, thereby further highlighting the vital role of the electrode morphology in improving the electrochemical performance of $\mathrm{Li}-\mathrm{S}$ batteries.

${ }^{a}$ Faculty of Applied Science, Delft University of Technology, The Netherlands. E-mail: $d$. p.singh@utwente.nl

${ }^{b} \mathrm{MESA}^{+}$, University of Twente, Enschede, The Netherlands

'Institute for Materials Research and Innovation (IMRI), University of Bolton, Bolton BL3 5AB, UK. E-mail:n.soin@bolton.ac.uk

${ }^{d}$ Nanotechnology and Bioengineering Centre (NIBEC), University of Ulster, Jordanstown, BT37 OQB, UK

${ }^{e}$ School of Biosciences, University of Birmingham, Edgbaston, Birmingham B15 2TT, UK

${ }^{f}$ Kavli Institute of Nanoscience, Delft University of Technology, The Netherlands ${ }^{g}$ Department of Physics, School of Natural Sciences, Shiv Nadar University, Gautam Buddha Nagar, Uttar Pradesh, 201314, India

$\dagger$ Electronic supplementary information (ESI) available. See DOI: $10.1039 / \mathrm{c} 7 \mathrm{se} 00195 \mathrm{a}$

\section{Introduction}

As the next-generation energy storage materials, lithium-sulfur (Li-S) batteries have become increasingly attractive owing to their high gravimetric density (2600 $\left.\mathrm{W} \mathrm{h} \mathrm{kg}^{-1}\right)$ and specific capacity $\left(1671 \mathrm{~mA} \mathrm{~h} \mathrm{~g}^{-1}\right.$ ), in addition, sulfur is a highly costeffective and environmentally benign element. ${ }^{\mathbf{1}}$ However, the overall performance of current $\mathrm{Li}-\mathrm{S}$ batteries is impeded by inherently poor electronic and ionic conductivity of sulfur and the dissolution of higher-order polysulphides phases $\left(\mathrm{Li}_{2} \mathrm{~S}_{n}(8 \geq\right.$ $n \geq 2$ )) during potential cycling which cause irreversible loss of active material. This is especially so for the conventional $\mathrm{Li}-\mathrm{S}$ battery cathodes, consisting of sulfur, conductive carbon and binder, where it is difficult to suppress the dissolution of lithium polysulfide in liquid electrolyte and stabilize the active material in the cathode matrix. During the continuous chargedischarge cycles, these polysulfides diffuse into liquid electrolyte and shuttle through the separator to lithium anode, and finally precipitate as an insulating layer $\left(\mathrm{Li}_{2} \mathrm{~S}_{2}\right.$ and/or $\left.\mathrm{Li}_{2} \mathrm{~S}\right)$ over the electrodes. ${ }^{2-5}$ With increasing current density and chargedischarge cycles, this further increases the interfacial charge transfer resistance, lowers the overall columbic efficiency and degrades the rate and life cycle performance. ${ }^{6-10}$

To expedite the reversible electrochemical reaction and to achieve high rate performance, both the sulfur and polysulphides must maintain the ionic and electronic conduction within the electrode matrix. ${ }^{\mathbf{6}, 11}$ This requires: (i) confining the insulating sulfur and polysulfide shuttles in electronically conductive electrode matrix, (ii) facile ionic network around encapsulated sulfur formed by the liquid electrolyte in the pores of the composite electrode matrix and (iii) efficient charge transfer reaction between the liquid electrolyte and the active material. To this effect, various matrices including mesoporous carbons, ${ }^{11,12}$ microporous carbon spheres, ${ }^{13,14}$ nanotube/ fibres, ${ }^{15,16}$ activated carbon $;{ }^{17}$ polar metal oxides such as $\mathrm{TiO}_{2}$, $\mathrm{SiO}_{2}, \mathrm{Al}_{2} \mathrm{O}_{3},{ }^{18,19}$ have been investigated. More recently, quasi-2-D metal carbides (such as $\mathrm{Ti}_{2} \mathrm{C}$ ) and the 2-D nanosheets of reduced Graphene Oxide (rGO), ${ }^{20-22}$ owing to their superior 
electrical conductivity, large surface area and surface tailorability, have emerged as promising materials for confining lithium polysulphides while improving the material utilisation, rate and cyclic stability. ${ }^{23}$ It is well established that the applications of $\mathrm{sp}^{2}$ carbon in the area of energy storage are highly dependent not only on their superior intrinsic physical properties, such as mechanical strength, electrical and thermal conductivity, but also on their tunable chemical properties. ${ }^{24-26}$ Recent reports have shown that the surface modified carbon fibres, graphene oxide sheets and polymer coatings facilitate better polysulfide anion adhesion on the surface, thereby enhancing the active material utilisation and life cycle capability. ${ }^{27,28}$ Studies have shown that besides physically confining elemental sulfur and lithium polysulfides in the meso/ microporous frameworks, the performance of liquid electrolyte based batteries is also governed by electrode morphology. Furthermore, higher performance requires facile ionic (through liquid electrolyte) and electronic transport (through conductive additive).$^{29-33}$ Pioneering work by Nazar et al. has established the close relationship between the electrode microstructure and the subsequent electrochemical performance, which further necessitates the demand for microstructured electrodes with enhanced ionic and electronic tortuosity combined with high sulfur loading. ${ }^{6,11,19,34,35}$ Thus, it is still an on-going challenge to prepare high performance electrodes with high specific capacity at high rates due to shorter diffusion lengths and reduced interfacial contact resistance.

Herein, we report novel binder-free 3-D vertically aligned electrodes of few layered graphene (FLG) nanoflakes with
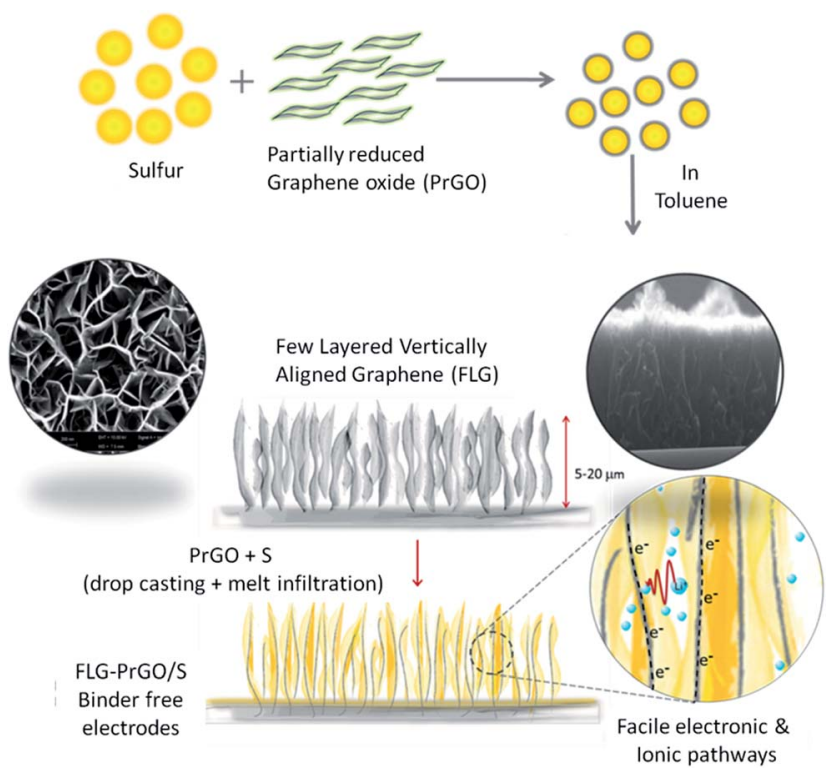

Fig. 1 Schematic illustration of the preparation of PrGO/S composite and fabrication vertically aligned FLG/PrGO-S electrode via drop casting and melt infiltration method. Top and cross sectional scanning electron micrograph of FLG electrode shows the interconnected network of micro voids/channels and the high aspect ratio of graphene sheets. Furthermore, the proposed facile (electronic and ionic) charge transport within interconnected porous structures is illustrated. interconnected micro voids/channel, filled with partially reduced graphene oxide-sulfur (PrGO-S) nanocomposites for high performance Li-S batteries (schematic shown in Fig. 1). The melt-infiltrated PrGO-S nanocomposites (see ESI $\dagger$ ) within a vertically aligned FLG network, provide several key advantages over the conventional 2-D planar electrode morphology, including: (i) facilitation of improved electrical conductivity and high sulfur loading ( $\sim 80$ wt $\%$ wrt PrGO/FLG as confirmed by TGA (ESI, Fig. S1†)) in the interconnected micro-porous FLG network; (ii) ease of electrolyte accessibility owing to its highly interconnected nature and (iii) uniform distribution of voids/ channels confining the polysulfide shuttle within the cathode matrix and improving the active material utilisation to facilitate facile ionic and electronic pathways. ${ }^{16,36,37}$ This simple and facile method to fabricate the 3-D FLG/PrGO-S electrodes offers great flexibility in controlling and tuning of electrode thickness and free volume based on the variation of growth parameters of the FLGs (see ESI, Fig. S2 $\dagger$ ). Furthermore, the presence of epoxide (C-O-C), hydroxyl $(-\mathrm{OH})$ and carboxyl $(-\mathrm{COOH})$ groups on the PrGO surface is expected to further enhance the sulfur and lithium polysulfide immobilization during the discharge process. Drop casting of PrGO/S nanocomposite on the FLG is expected to have additional advantages; firstly, the large surface area of PrGO will act as a barrier layer between the electrode and electrolyte; with the functional groups such as epoxide, hydroxyl and carboxyl on the PrGO physically sandwiching the sulfur (and its polysulfides) within the micro void/channelled FLG structure. Secondly, the epoxide groups on the PrGO surface further enhances the immobilization of sulfur and polysulfides during the discharge process. ${ }^{38}$

\section{Experimental}

\subsection{Synthesis of partially reduced graphene oxide}

Graphene oxide was synthesised using a modified Hummers' method..$^{39,40}$ For the preparation of partially reduced graphene oxide, the as prepared GO was reduced using L-ascorbic acid (L-AA) as reported in the literature. ${ }^{41,42}$ Typically, $0.1 \mathrm{mg} \mathrm{mL}^{-1}$ aqueous solution of GO was prepared and L-AA was added such that the GO:L-AA ratio was $1: 10$. Upon complete dissolution of L-AA in the GO solution, the mixture was further heated for 60 minutes at $95{ }^{\circ} \mathrm{C}$ with continuous stirring. As the reaction took place, the brown solution was no longer homogeneous and black precipitates started to appear. Upon the completion of reaction, the solution was cooled down and the precipitate was separated and washed repeatedly with water using filtration and centrifugation. The material thus obtained (PrGO) was dried overnight in a vacuum oven $\left(50{ }^{\circ} \mathrm{C}\right)$ for further use.

\subsection{Synthesis of vertically aligned few layer graphene nanoflakes}

The growth of few layered graphene (FLG) nanoflakes was carried out in a $1.5 \mathrm{~kW}, 2.45 \mathrm{GHz}$ SEKI microwave plasma enhanced chemical vapour deposition system. ${ }^{\mathbf{4 3 4 4}}$ Stainless steel substrates (SS316L) cleaned using acetone and 
isopropanol alcohol were used as substrates, which were placed on top of a Si wafer to allow plasma irradiation to higher temperatures. Once the samples were loaded, the chamber was pumped down to a base pressure of $\sim 2 \times 10^{-3}$ Torr after which nitrogen $\left(\mathrm{N}_{2}\right)$ plasma pre-treatment of substrate was carried out at $700 \mathrm{~W}$ for certain duration of time. $\mathrm{CH}_{4}$ was then injected at the end of pre-treatment time while the microwave power was simultaneously increased to $800 \mathrm{~W}$. During the growth time of 60 seconds, the substrate temperature exceeded $1250{ }^{\circ} \mathrm{C}$ as monitored by an optical pyrometer mounted on top of the chamber. Post deposition, the samples were allowed to cool down to room temperature under a $\mathrm{N}_{2}$ atmosphere. The vertical alignment of the resulting nanostructures is a unique feature of the microwave plasma CVD route. Unlike the thermal CVD route wherein the alignment is due to the crowding and van der Waals forces, the alignment in microwave CVD route is attributed to the plasma induced electric field effects and has been discussed in detail in our previous works. ${ }^{43,44}$ It should be noted that the microwave plasma deposition route can be used for catalyst free growth of graphene nanoflakes on any substrate which can sustain the high temperatures and plasma bombardment encountered during the growth process such as metallic foils, carbon cloth etc.

\subsection{Preparation of vertically aligned FLG/PrGO-S electrodes}

The fabrication of vertically aligned FLG/PrGO-S electrode involves the following two steps. Firstly, predetermined amounts of commercially available sulfur (93 wt\%) (Sigma Aldrich) and synthesised PrGO powders (7 wt\%) were mixed in toluene ( $0.1 \mathrm{gm}$ of PrGO/S in $50 \mathrm{~mL}$ of toluene) and ball milled using a Fritsch planetary ball-mill under an argon atmosphere for 60 to 90 minutes to obtain a homogenous mixture. This was followed by melt infiltration at $130{ }^{\circ} \mathrm{C}$ under argon atmosphere with subsequent drop casting of $\mathrm{PrGO} / \mathrm{S}$ on the vertically aligned FLGs to prepare the binder-free 3-D FLG/PrGO-S electrodes.

\subsection{Microstructural characterisation}

Structural studies on the 3-D FLG/PrGO-S electrodes were performed using Titan Cubed Cs corrected electron microscope with a resolution of $0.08 \mathrm{~nm}$. Inbuilt high resolution EDX was used for mapping the distribution of carbon and sulphur. X-ray photoelectron spectroscopy (XPS) was performed on a Kratos Axis Ultra utilising an $\mathrm{Al} \mathrm{K} \alpha$ radiation source (1486.6 eV). XPS spectra were obtained with a spot size of $200 \mu \mathrm{m}$. High resolution scans of individual elements and the survey spectra were measured at a pass energy of $50 \mathrm{eV}$ and $200 \mathrm{eV}$, respectively. The scans were averaged over 10 sweeps. Thermo Nicolet Nexus 670 FT-IR spectrometer was used for FTIR studies wherein the spectra was measured for 128 scans (DRIFT mode) at a resolution of $\pm 4 \mathrm{~cm}^{-1}$. The thermogravimetric analysis of the sulfur content in the PrGO/S electrodes was measured using TGA carried out on a Netzsch5 STA F3 system. The measurement was carried out from room temperature until $800{ }^{\circ} \mathrm{C}$ at $5{ }^{\circ} \mathrm{C} \mathrm{min}^{-1}$ ramp rate in air.

\subsection{Electrochemical measurements}

The vertically aligned 3-D FLG/PrGO-S electrodes were tested within the voltage range of 1.8-2.6 $\mathrm{V}$ against lithium metal using Maccor Battery Tester. Prior to electrochemical testing, electrodes were dried in vacuum. Cells were assembled using a homemade vacuum flange type assembly in an argon-filled
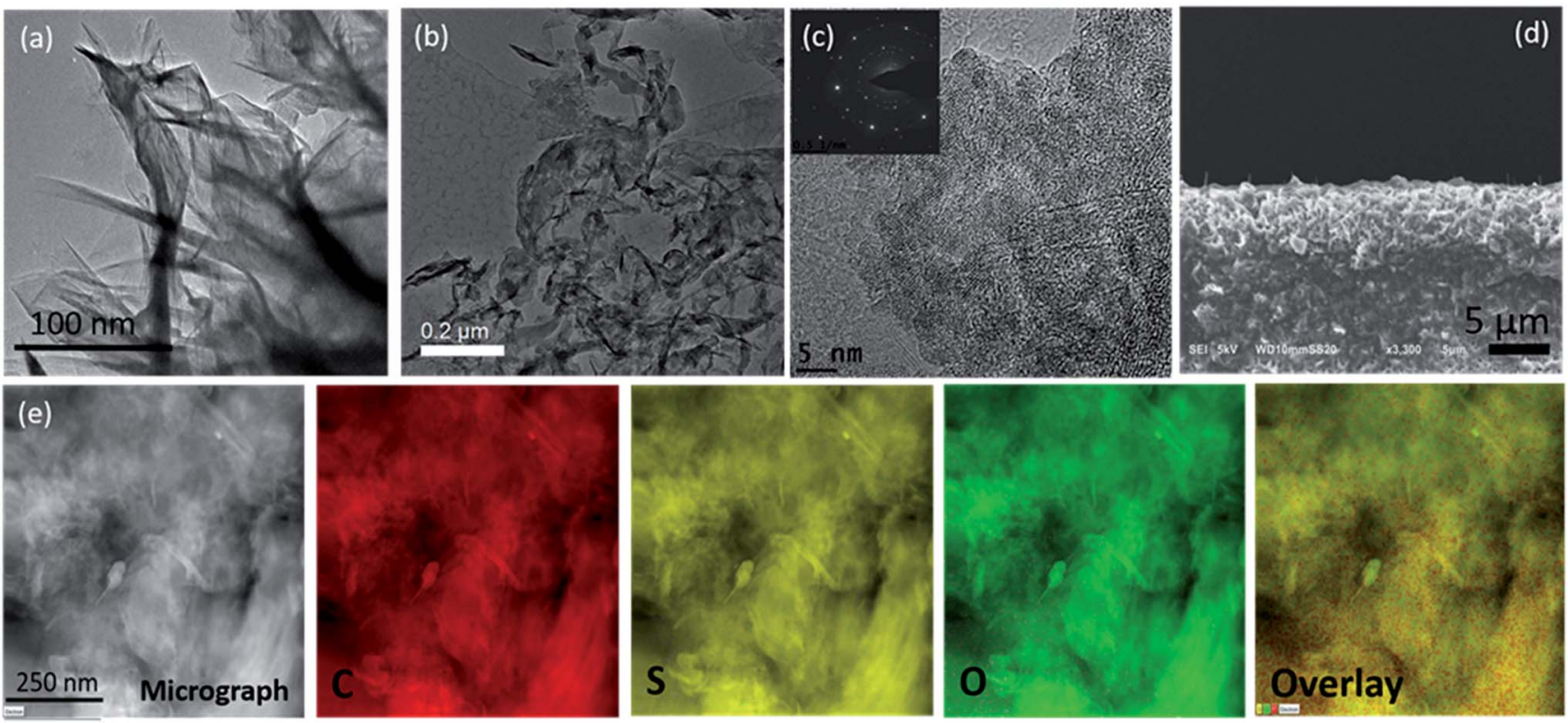

Fig. 2 (a) TEM image of pristine FLG showing the variation of graphene layers with a knife-edge like structure, (b and c) low and high magnification TEM image of PrGO-S nanocomposite with the inset showing the diffraction pattern corresponding to crystalline nature of the composite, inset in (c): selected area diffraction pattern (d) cross-sectional SEM image of the 3-D FLG PrGO/S electrode, (e) dark-field STEM image of nanocrystalline sulfur wrapped inside the PrGO sheet with the corresponding elemental mapping demonstrating the uniform coating of sulfur for the PrGO/S nanocomposites. The TEM-EDX is provided in ESI Fig. S4. $\dagger$ 
glove box using polypropylene separator. The electrolyte used was $1.0 \mathrm{M}$ lithium bis-trifluoromethanesulfonylimide (LiTFSI) in 1,3-dioxolane and 1,2-dimethoxyethane ( $1: 1$ by volume) with $3 \mathrm{wt} \% \mathrm{LiNO}_{3}$ additive. ${ }^{45}$ To completely wet the electrode, approximately $100 \mu \mathrm{l}$ of electrolyte was used. To compare the effect of 3D electrode morphology, a standard PrGO/S composite ( 85 wt\% sulfur) electrode was prepared by mixing PrGO/sulfur composite with 85 wt\% sulphur and carbon black (5 wt\%) with PVDF (10 wt\%) binder in NMP and casted onto carbon coated copper foil.

\section{Results and discussion}

Fig. 2(a) shows the transmission electron microscopy (TEM) image of the pristine FLGs, wherein the samples show a predominantly knife-edge structure with a thick (15-20 nm) base constantly narrowing down as it goes along the axial growth direction till it reaches the top with 1-3 layered graphene. ${ }^{\mathbf{4 3 , 4 4}}$ It should be noted that these highly interconnected FLGs synthesised (areal mass density $\left(0.073 \mathrm{mg} \mathrm{cm}^{-2}\right)$ ) using a microwave plasma technique are largely composed of carbon only (98.8 at\%) with a small amount of adsorbed oxygen (1.2 at\%) (see Fig. S3†). ${ }^{43,44}$ For the PrGO/S composites, Fig. 2(b-d) shows the sub-micrometer sulfur particles wrapped by partially reduced graphene oxide (PrGO) sheets with the elemental mapping revealing a homogenous dispersion of sulfur on the PrGO sheets. Owing to the melt infiltration process utilised for the 3-D FLG/PrGO-S synthesis, a thin layer of sulfur nanoparticles as well as larger discrete particles were observed embedded in the matrix as evident from the elemental mapping and energy dispersive X-ray (EDX) analysis, which further confirms the high sulfur/carbon ratio (see Fig. S4, ESI $\dagger$ ). For the 3-D FLG/PrGO-S electrodes, the mild L-ascorbic acid reduction (starting GO, $\mathrm{C}: \mathrm{O}=2.1$ ) led to the removal of a significant amount of oxygen functional groups (PrGO, $\mathrm{C}: \mathrm{O}=4.6$ ) leaving behind residual $\mathrm{C}-\mathrm{O}-\mathrm{C},-\mathrm{COOH}$ and $-\mathrm{C}=\mathrm{O}$ groups (Fig. 3(a)). ${ }^{\text {41,43-47 }}$ These residual groups have been previously suggested to immobilise sulfur and subsequently free lithium polysulfides during the charging-discharging process. ${ }^{24,38,48}$ Furthermore, peaks attributed to $-\mathrm{S}-\mathrm{O}-$ bonding were observed in both the $\mathrm{S} 2 \mathrm{p}$ (164.6 and $165.5 \mathrm{eV}$ ) and $\mathrm{O}$ 1s spectrum ( $\sim 530.6 \mathrm{eV}$, Fig. S3, ESI $\dagger$ ), thus confirming the electronic interactions occurring between sulfur and the PrGO matrix (Fig. 3(b)). ${ }^{49}$ The presence of the $-\mathrm{S}-\mathrm{O}-$ bonding was further corroborated by Fourier Transform Infra-red Spectroscopy (FTIR) studies, which revealed peak at $1030 \mathrm{~cm}^{-1}$ (Fig. S5, ESI $\dagger$ ). Similar results of interaction between GO and sulfur have been reported by Li et al. ${ }^{49}$ and Guo et al. ${ }^{50}$ wherein the $-\mathrm{S}-\mathrm{O}$ bonding helps in anchoring sulfur and intermediate polysulfide products during the cycling process. Recent reports have utilised the epoxide and hydroxyl groups on the basal plane of GO in addition to the edge dominant carbonyl and carboxyl groups for the immobilisation of sulfur and its discharge products. ${ }^{51}$ However, the presence of these functional groups also leads to the poor electronic conductivity of GO. ${ }^{24,51}$ Thus, for most of the previous reports with $\mathrm{GO} / \mathrm{S}$ composites, the achieved rate performances are generally below the rate of $2 \mathrm{C}(1 \mathrm{C}=1675 \mathrm{~mA}$ $\left.\mathrm{g}^{-1}\right) .^{24,52}$ On the contrary, reduced GO (RGO) or graphene with intrinsically higher electronic conductivity has also been employed to prepare RGO/S or G/S composites for improving rate performance. ${ }^{24}$ However, RGO or graphene does not have the abundant functional groups that can bind sulfur and its discharge products. Thus, to obtain the optimal balance of the presence of functional groups and the electronic conductivity of the graphene matrix, the partially reduced graphene oxide (PrGO) is ideal. The electrochemical performance of the 3-D FLG/PrGO-S electrode was evaluated using galvanostatic discharge-charge measurements at variable current densities from $80 \mathrm{~mA} \mathrm{~g}^{-1}(\mathrm{C} / 20)$ to $8000 \mathrm{~mA} \mathrm{~g}^{-1}$ (5C) within the voltage window of 1.8 to $2.6 \mathrm{~V}$ versus $\mathrm{Li} / \mathrm{Li}^{+}$. As shown in Fig. 4, the first discharge of PrGO/FLG-S electrode at C/20 illustrates the typical two step charge discharge behaviour shown by Li-S batteries (corresponding to the conversion of elemental sulfur into longchained $\left(\operatorname{Li}_{2} \mathrm{~S}_{n}, 4 \leq n \leq 8\right)$, and short chained $\left(\operatorname{Li}_{2} \mathrm{~S}_{n}, n<4\right)$ polysulfides), and a significantly high discharge capacity of 1350 $\mathrm{mA} \mathrm{h} \mathrm{g}^{-1}$ at $\sim 80 \mathrm{wt} \%$ sulfur loading was achieved. This is higher than the value reported for electrochemically synthesised vertically aligned sulfur-graphene nanowalls (1261 $\mathrm{mA} \mathrm{h} \mathrm{g}^{-1}$ at C/8). ${ }^{49}$ Similarly, Wang et al. reported a first discharge capacity of $1611 \mathrm{~mA} \mathrm{~h} \mathrm{~g}^{-1}$ albeit at a much slower rate of $50 \mathrm{~mA} \mathrm{~g}^{-1}(\mathrm{C} / 33) .{ }^{53} \mathrm{Ni}$ et al. reported sulfur-rGO nanocomposites with a high initial discharge capacity of $\sim 1473 \mathrm{~mA} \mathrm{~h}$ $\mathrm{g}^{-1}$ at $0.1 \mathrm{C}$ but after subsequent cycles at the same C-rate, the discharge capacity of their electrodes dropped to $1230 \mathrm{~mA} \mathrm{~h}$
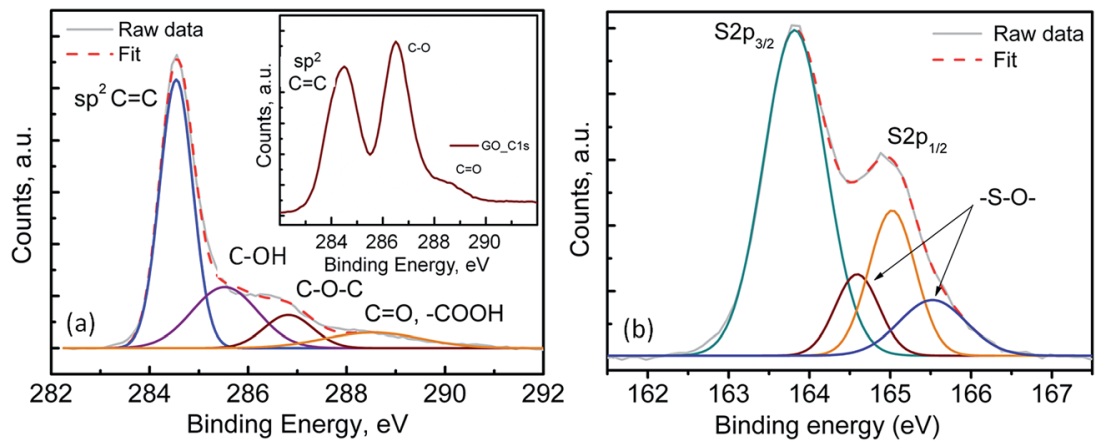

Fig. 3 X-ray photoelectron spectra of 3-D FLG PrGO/S electrode, (a) deconvolution of C 1s core level spectra of PrGO, inset shows the C 1s spectra of pristine $\mathrm{GO}$, (b) deconvolution of the $\mathrm{S} 2 \mathrm{p}$ spectra showing the $-\mathrm{S}-\mathrm{O}$ - bonding for the PrGO-S nanocomposites. 


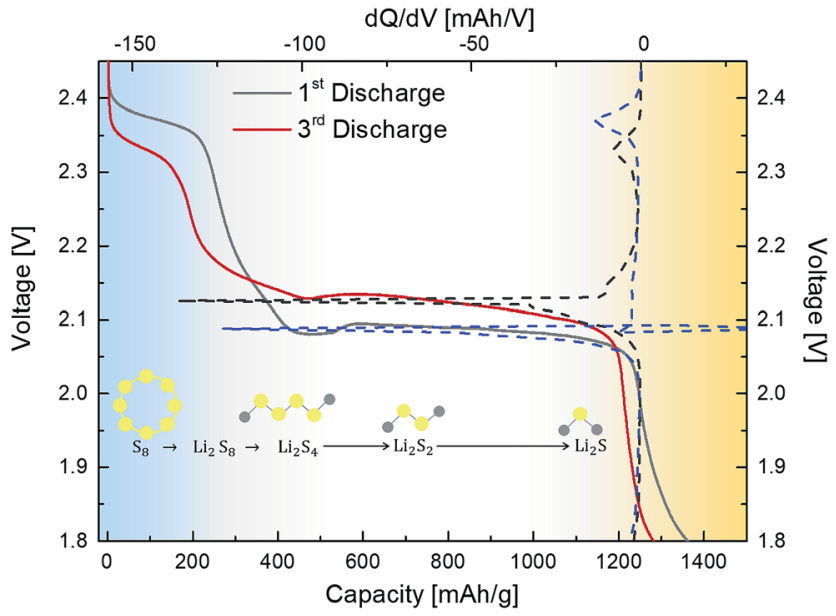

Fig. 4 Discharge voltage profile of the 3-D FLG PrGO/S electrode at $\mathrm{C} / 20$ within the voltage window of $2.6-1.8 \mathrm{~V}$ (vs. Li) combined with the corresponding differential capacity plot on the top axis. Typical voltage vs. capacity profiles illustrating typical conversion of elemental sulfur to polysulfide anion during various stage of discharge. (I) The conversion of solid sulfur to soluble polysulphides; (II) conversion of polysulphides to solid $\mathrm{Li}_{2} \mathrm{~S}_{2}$; (III) conversion of solid $\mathrm{Li}_{2} \mathrm{~S}_{2}$ to solid $\mathrm{Li}_{2} \mathrm{~S}$.

$\mathrm{g}^{-1} \cdot{ }^{54}$ For the first and third discharge cycles (Fig. 4), it can be observed that the voltage plateau and corresponding cathodic peak shifts (from $2.08 \mathrm{~V}$ to $2.1 \mathrm{~V}$ and from $2.35 \mathrm{~V}$ to $2.38 \mathrm{~V}$ ) towards equilibrium. This shift in cathodic peak could be attributed to the lowering of internal resistance of the cell due to the conversion of 'insulating' elemental sulfur present in the electrode into the polysulfide species, followed by their subsequent dissolution into the liquid electrolyte (resulting into slightly shorter voltage plateau and lower capacity). ${ }^{54}$ Furthermore, an intermediate discharge plateau and corresponding cathodic peak at $2.15 \mathrm{~V}$ was observed, resulting in a three-step discharge profile, which is consistent with earlier reports..$^{55,56}$ This intermediate peak has only been observed in first few charge-discharge cycles and disappears with subsequent cycles as shown in Fig. S7 (ESI $\dagger$ ). Barchasz et al. have previously shown that this intermediate cathodic peak at $\sim 2.1 \mathrm{~V}\left(v s . \mathrm{Li} / \mathrm{Li}^{+}\right)$is due to the formation of $\mathrm{S}_{4}{ }^{2-}$ and $\mathrm{S}_{3}{ }^{2-}$ species resulting from the reduction of the $\mathrm{S}_{6}{ }^{2-}$ and $\mathrm{S}_{3}{ }^{--}$species formed at first discharge plateau. ${ }^{55}$ Interestingly, they have observed this intermediate peak only at high scan rates for electrodes with high carbon content, whereas the peak started to disappear as the carbon content in electrode decreased..$^{55}$ Considering the PrGO/FLG electrodes in this study have only $20 \%$ carbon content, the presence of this intermediate peak (at $2.15 \mathrm{~V}$ ) even at low currents $(\mathrm{C} / 20)$ is attributed to the enhanced sulfur immobilisation within the PrGO/FLG matrix due to the presence of oxygen functional (carbonyl and carboxyl) groups, which actively form S-O bonds facilitating the chemical adsorption of sulfur. As discussed above (XPS, Fig. 3), Song et al. too have evidenced the formation of $\mathrm{S}-\mathrm{O}$ bonds between the oxygen functional groups and sulfur due to the low enthalpy changes required for such bond formation, through X-ray absorption and density functional theory investigations..$^{57}$ In our case, the
PrGO shows a significant oxygen content ( $\mathrm{C}: \mathrm{O}$ ratio of 4.6), as compared to the pristine $\mathrm{GO}$ (C : O ratio of 2.1) which provides the conductive, high surface area and alongside the FLGs, further decreases the need for a large amount of carbon to immobilize the high S-content.

After a few charge-discharge cycles at $\mathrm{C} / 20$, the same 3-D PrGO/FLG-S electrode was further tested at different $\mathrm{C}$ rates (C/ 10 to $5 \mathrm{C}$ ). As the current density was increased to $\mathrm{C} / 10$, the specific capacity dropped to $\sim 1160 \mathrm{~mA} \mathrm{~g}^{-1}$ (Fig. 5). However, even after 350 cycles, the 3-D FLG/PrGO-S electrode still retained an excellent discharge capacity of $\sim 1040 \mathrm{~mA} \mathrm{~h} \mathrm{~g}^{-1}$ and 880 $\mathrm{mA} \mathrm{h} \mathrm{g}{ }^{-1}$ at $\mathrm{C} / 10$ and $1 \mathrm{C}$, respectively. The values thus obtained at $\mathrm{C} / 10$ are higher than those observed for 3-D vertically aligned interconnected carbon nanosheets infiltrated with nearly 70 wt $\%$ sulfur, ${ }^{58}$ interleaved expanded graphite-embedded sulfur nanocomposite ${ }^{59}$ and are comparable to those obtained utilising a binder-free polymer encapsulated sulfur in an aligned CNT matrix. ${ }^{60}$ Interestingly, as the charge current density further increased to $2 \mathrm{C}$ and $5 \mathrm{C}$ (constant discharge at $\mathrm{C} / 5$ ), the 3-D FLG/PrGO-S electrode continued to deliver high specific capacity of $\sim 830 \mathrm{~mA} \mathrm{~h} \mathrm{~g}{ }^{-1}$ and $700 \mathrm{~mA} \mathrm{~h} \mathrm{~g}{ }^{-1}$, respectively (Fig. 5). However, in the case of high $\mathrm{C}$ rates, contrary to the slow
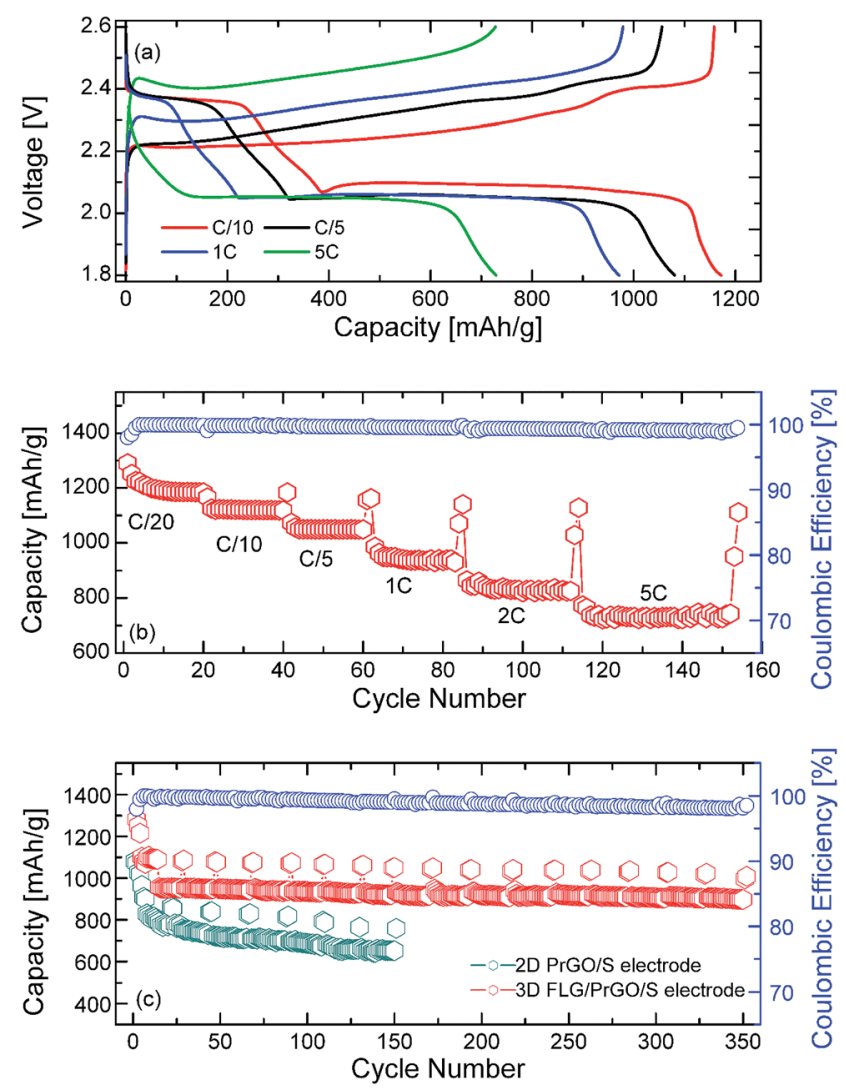

Fig. 5 (a) Charge and discharge profile of the 3-D FLG PrGO/S electrode at different rates from $\mathrm{C} / 10$ to $5 \mathrm{C}$, (b) rate performance and corresponding coulombic efficiency of the FLG/PrGO-S electrode at different charging discharging rates, (from $1 \mathrm{C}$ to $5 \mathrm{C}$ rate, electrodes were discharged at $C / 10$ ), (c) life cycle profile of 2-D PrGO/S and 3-D FLG/PrGO-S electrodes at $\mathrm{C} / 10$ and $1 \mathrm{C}$ rate with corresponding coulombic efficiency calculations for the 3-D FLG/PrGO-S electrodes. 


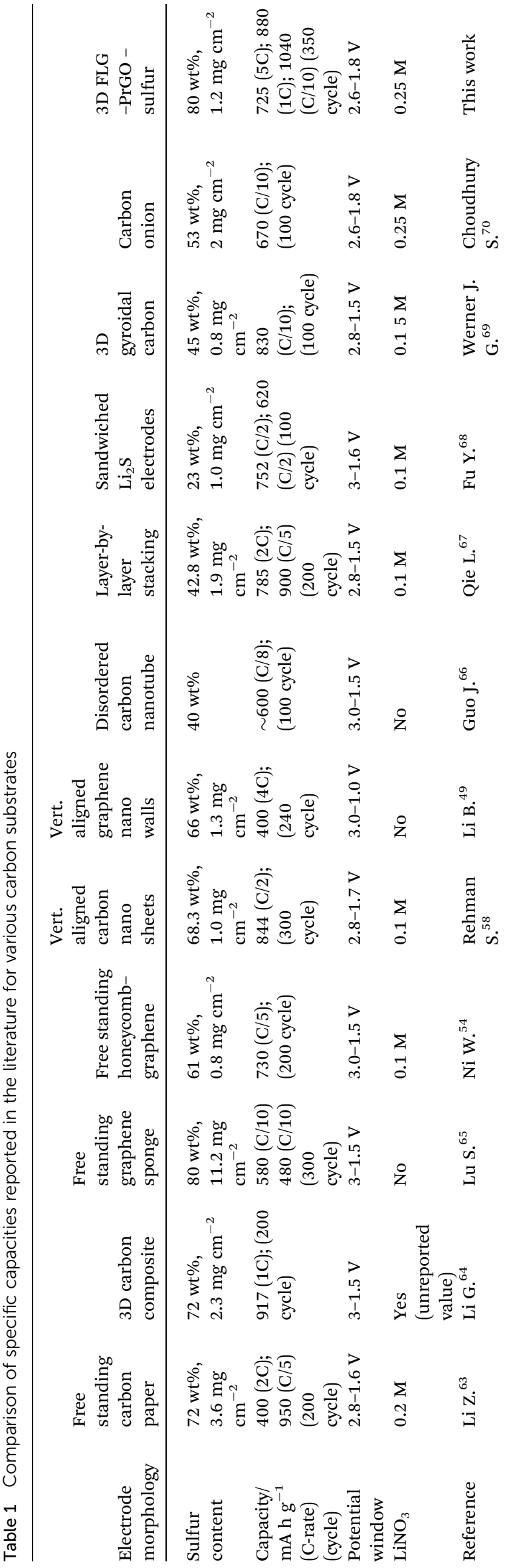

$\mathrm{C}$ rate $(\mathrm{C} / 20)$ charge-discharge profile where the second discharge plateau is almost three times that of the first plateau, it seems that the first plateau $\left(2.35 \mathrm{~V} v s . \mathrm{Li}^{2} \mathrm{Li}^{+}\right)$almost disappeares at the $5 \mathrm{C}$ rate, thereby making the second plateau appear to be larger than the first. This reduction of first plateau may be because of the intermediate species (such as unstable polysulfides and radicals $\left(\mathrm{S}_{3}{ }^{-}\right)$) not getting enough time to evolve and actively participate in the electrochemical reaction. Similar modified (dis)charge profiles at high $\mathrm{C}$ rate have been observed in previous reports as well. ${ }^{\mathbf{6 3}, 64}$ Nonetheless, various complex processes are involved during charge-discharge of $\mathrm{Li}-\mathrm{S}$ battery and are affected by factors such as scan rate, dissolution of active material in electrolyte, sulfur to carbon ratio, additives etcetera. Specifically identifying a single factor for charge discharge behaviour at high $\mathrm{C}$ rate requires further extensive analysis. As compared to the other reported values of $400 \mathrm{~mA} \mathrm{~h}$ $\mathrm{g}^{-1}$ @8C, and $315 \mathrm{~mA} \mathrm{~h} \mathrm{~g}{ }^{-1}$ @2C, $738 \mathrm{~mA} \mathrm{~h} \mathrm{~g}{ }^{-1}$ @3C, these are highly appreciable values. ${ }^{\mathbf{4 9 , 5 1 , 5 8}}$ Such excellent rate capability at high currents in 3-D electrodes can be attributed to low chargetransfer resistance (both ionic and electronic resistance) and low lithium polysulfide dissolution. ${ }^{59,61,62}$ The discharge performance of the planar 2-D PrGO/S composites with equivalent sulfur loading $(\sim 80 \mathrm{wt} \%)$ was carried out using similar charge-discharge sequences as that for the 3-D FLG/PrGO/S electrodes. The 2-D PrGO/S electrode showed an initial discharge capacity of $1080 \mathrm{~mA} \mathrm{~h} \mathrm{~g}^{-1}$ at $\mathrm{C} / 10$ rate, as compared to an initial value of $1320 \mathrm{~mA} \mathrm{~h} \mathrm{~g}{ }^{-1}$ for the 3D FLG/PrGO-S electrode, as shown in Fig. 5. However, after subsequent cycles, the capacity continued to drop, suggesting dissolution of soluble Lipolysulfides in liquid electrolyte, causing irreversible loss of active material from the cathode. ${ }^{34}$ In fact, as the charge current density increased from $\mathrm{C} / 10$ to $1 \mathrm{C}$, the capacity continued to drop, and just after 150 cycles, the 2-D planar geometry electrodes could deliver only $\sim 560 \mathrm{~mA} \mathrm{~h} \mathrm{~g} \mathrm{~g}^{-1}$. This significant difference (of $>200 \mathrm{~mA} \mathrm{~h} \mathrm{~g}^{-1}$ ) in the capacity of planar PrGO-S electrodes, and excellent cycling and rate performances demonstrated by the 3-D FLG/PrGO-S electrodes corroborates our earlier assumption that the 3-D microstructure with interconnected ionic and electronic transport pathways lowers the overall charge transport resistance and facilitates excellent electrical and ionic transport in entire electrode matrix. ${ }^{58-61}$ Additionally, a comparison of specific capacities from the literature with different types of carbon substrates can be found in Table 1. It can be clearly observed from the table the 3-D FLG/ PrGO-S electrode offers some of the highest reported values for the Li-S electrodes. For both the 3-D and 2-D electrodes, the role of residual functional groups on the surface is of crucial importance. For pristine graphene oxide, lack of sufficient $\pi$ conjugation leads to poor electronic conductivity and as such it cannot be used for $\mathrm{Li}-\mathrm{S}$ batteries. ${ }^{2,47,48}$ However, upon controlled reduction, the aromatic $\pi-\pi$ bonding is partially restored, leading to improved conductivity. The residual oxygen functional groups on the PrGO not only provide the lithium polysulfide occupying sites but also the requisite hydrophilicity to facilitate the adsorption of such polysulfides. ${ }^{24,38,48}$

Furthermore, the post-mortem SEM (Fig. S6, ESI $\dagger$ ) revealed that the 3-D FLG/PrGO-S electrode maintained excellent 
structural integrity even after 350 cycles at $1 \mathrm{C}$, suggesting that the substantial micro-porosity within the FLG structure compensates the volume changes of sulfur during polysulfide formation. Moreover, as seen in the cross-sectional FIB milled image, Fig. S6(b), $\uparrow$ the FLG structural morphology post-mortem, displays a marked difference for infiltrated samples as compared to pristine FLGs. The residual functional groups on the PrGO surface especially $\mathrm{C}-\mathrm{O}$ and $-\mathrm{COOH}$ can act as the reaction centres with $\mathrm{Li}^{+}$ions by rapidly and reversibly capturing them through surface absorption and surface redox reaction. Furthermore, with the on-going optimisation of height and porosity of the underlying FLG electrodes being currently undertaken, it is expected that the electrochemical performance of these 3D FLG/PrGO/S electrodes can be enhanced even further.

\section{Conclusions}

In conclusion, hybrid 3-D electrode structures consisting of FLGs melt-impregnated with PrGO-sulfur nanocomposites were successfully prepared with a high sulphur loading of $\sim 80 \mathrm{wt} \%$. The 1-3 layered FLGs with a predominantly knife-edge structure were synthesised using a microwave plasma technique and largely composed of carbon (98.8 at\%) with a small amount of adsorbed oxygen (1.2 at\%). The melt infiltration process enabled deposition of a thin layer of sulfur nanoparticles as well as larger discrete particles embedded in the PrGO matrix as evident from the elemental mapping and EDX, which also confirmed the high sulfur/carbon ratio. Through the use of these multifunctional nanocomposites, a judicious balance of surface oxygen functional groups and 3-D architecture was achieved. This unique combination was able to facilitate electronic, ionic transport and ease of electrolyte accessibility along with confinement of the polysulfide shuttles within the matrix leading to excellent cycling capabilities. The resultant electrode not only displayed a high discharge capacity of $1350 \mathrm{~mA} \mathrm{~h} \mathrm{~g} \mathrm{~g}^{-1}$ but also exhibited excellent capacity of $\sim 80 \%$ even after 350 cycles with $\sim 1040 \mathrm{~mA} \mathrm{~h} \mathrm{~g}^{-1}$ and $880 \mathrm{~mA} \mathrm{~h} \mathrm{~g}^{-1}$ at C/10 and 1C, respectively. On the other hand, comparative studies with 2-D planar PrGO-S electrodes displayed a relatively poor capacity retention of $560 \mathrm{~mA} \mathrm{~h} \mathrm{~g}{ }^{-1}$ after 150 cycles, suggesting limited charge transport within $2 \mathrm{D}$ electrode matrix and dissolution of lithium polysulfide in to liquid electrolyte. Thus, the current study highlights the importance of the electrode microstructure and the presence of surface functional groups to improve active material utilisation and charge discharge performance at high currents (C-rates). Furthermore, these initial results suggest the sincere need to build fundamental understanding to establish electrode structure and electrochemical performance relationship and is being further explored by the group.

\section{References}

1 M. Armand and J. M. Tarascon, Nature, 2008, 451, 652-657. 2 R. D. Rauh, F. S. Shuker, J. M. Marston and S. B. Brummer, J. Radioanal. Nucl. Chem., 1977, 39, 1761-1766.

3 H. Yamin and E. Peled, J. Power Sources, 1983, 9(3), 281-287.
4 R. D. Rauh, K. M. Abraham, G. F. Pearson, J. K. Surprenant and S. B. Brummer, J. Electrochem. Soc., 1979, 126(4), 523527.

5 S. S. Zhang, J. Power Sources, 2013, 231, 153-162.

6 X. Ji and L. F. Nazar, J. Mater. Chem., 2010, 20, 9821-9826.

7 A. Manthiram, Y. Fu, S.-H. Chung, C. Zu and Y.-S. Su, Chem. Rev., 2014, 114, 11751-11787.

8 J. A. Dean, Lange's Handbook of Chemistry, McGraw-Hill, New York, USA, 1999.

9 Y. V. Mikhaylik and J. R. Akridge, J. Electrochem. Soc., 2004, 151, A1969-A1976.

10 S. E. Cheon, K. S. Ko, J. H. Cho, S. W. Kim, E. Y. Chin and H. T. Kim, J. Electrochem. Soc., 2003, 150, A800-A805.

11 X. L. Ji, K. T. Lee and L. F. Nazar, Nat. Mater., 2009, 8, 500506.

12 K. Xi, S. Cao, X. Peng, C. Ducati, R. V. Kumar and A. K. Cheetham, Chem. Commun., 2013, 49, 2192-2194.

13 N. Jayaprakash, J. Shen, S. S. Moganty, A. Corona and L. A. Archer, Angew. Chem., Int. Ed., 2011, 50, 5904-5908.

14 C. Zhang, H. B. Wu, C. Yuan, Z. Guo and X. W. Lou, Angew. Chem., Int. Ed., 2012, 51, 9592-9595.

15 G. Zheng, Y. Yang, J. J. Cha, S. S. Hong and Y. Cui, Nano Lett., 2011, 11, 4462-4467.

16 S. Dörfler, M. Hagen, H. Althues, J. Tübke, S. Kaskel and M. J. Hoffmann, Chem. Commun., 2012, 48, 4097-4099.

17 R. Elazari, G. Salitra, A. Garsuch, A. Panchenko and D. Aurbach, Adv. Mater., 2011, 23, 5641-5644.

18 S. Evers and L. F. Nazar, Acc. Chem. Res., 2013, 46, 1135-1143. 19 C. J. Hart, M. Cuisinier, X. Liang, D. Kundu, A. Garsuch and L. F. Nazar, Chem. Commun., 2015, 51, 2308-2311.

20 G. He, C. J. Hart, X. Liang, A. Garsuch and L. F. Nazar, ACS Appl. Mater. Interfaces, 2014, 6, 10917-10923.

21 K. Xi, P. R. Kidambi, R. Chen, C. Gao, X. Peng, C. Ducati, S. Hofmann and R. V. Kumar, Nanoscale, 2014, 6, 5746-5753.

22 G. Zhou, L. C. Yin, D. W. Wang, L. Li, S. Pei, I. R. Gentle, F. Li and H. M. Cheng, ACS Nano, 2013, 7, 5367-5375.

23 X. Liang, A. Garsuch and L. F. Nazar, Angew. Chem., Int. Ed., 2015, 54, 3907-3911.

24 S. Yuan, Z. Guo, L. Wang, S. Hu, Y. Wang and Y. Xia, Adv. Sci., 2015, 2(8), 1500071.

25 C. Tang, Q. Zhang, M. Q. Zhao, J. Q. Huang, X. B. Cheng, G. L. Tian, H. J. Peng and F. Wei, Adv. Mater., 2014, 26(35), 6100-6105.

26 M. Q. Zhao, X. F. Liu, Q. Zhang, G. L. Tian, J. Q. Huang, W. Zhu and F. Wei, ACS Nano, 2012, 6(12), 10759-10769.

27 Z. Wang, Y. Dong, H. Li, Z. Zhao, H. B. Wu, C. Hao, S. Liu, J. Qiu and X. W. D. Lou, Nat. Commun., 2014, 5, 5002.

28 G. Zheng, Q. Zhang, J. J. Cha, Y. Yang, W. Li, Z. W. She and Y. Cui, Nano Lett., 2013, 13, 1265-1270.

29 A. Manthiram, S. H. Chung and C. Zu, Adv. Mater., 2015, 27, 1980-2006.

30 C. Fongy, A. C. Gaillot, S. Jouanneau, D. Guyomard and B. Lestriez, J. Electrochem. Soc., 2010, 157, A885-A891.

31 M. Gaberscek and J. Jamnik, Solid State Ionics, 2006, 177, 2647-2651.

32 D. P. Singh, F. M. Mulder, A. M. Abdelkader and M. Wagemaker, Adv. Energy Mater., 2013, 3, 572-578. 
33 P. A. Johns, M. R. Roberts, Y. Wakizaka, J. H. Sanders and J. R. Owen, Electrochem. Commun., 2009, 11, 2089-2092.

34 G. He, X. L. Ji and L. F. Nazar, Energy Environ. Sci., 2011, 4, 2878-2883.

35 J. Schuster, G. He, B. Mandlmeier, T. Yim, K. T. Lee, T. Bein and L. F. Nazar, Angew. Chem., Int. Ed., 2012, 51, 3591-3595.

36 X. Xiao, P. Liu, J. S. Wang, M. W. Verbrugge and M. P. Balogh, Electrochem. Commun., 2011, 13(2), 209-212.

37 N. Li, H. Song, H. Cui and C. Wang, Nano Energy, 2014, 3, 102-112.

38 C. Zu, L. Li, J. Guo, S. Wang, D. Fan and A. Manthiram, Phys. Chem. Lett., 2016, 7, 1392-1399.

39 S. Sharma, A. Ganguly, P. Papakonstantinou, X. Miao, M. Li, J. L. Hutchison, M. Delichatsios and S. Ukleja, J. Phys. Chem. C, 2010, 114(45), 19459-19466.

40 R. E. Priestley, A. Mansfield, J. Bye, K. Deplanche, A. B. Jorge, D. Brett, L. E. Macaskie and S. Sharma, RSC Adv., 2015, 5(102), 84093-84103.

41 J. Zhang, H. Yang, G. Shen, P. Cheng, J. Zhang and S. Guo, Chem. Commun., 2010, 46, 1112-1114.

42 M. J. Fernandez-Merino, L. Guardia, J. I. Paredes, S. VillarRodil, P. Solis-Fernandez, A. Martinez Alonso and J. M. D. Tascon, J. Phys. Chem. C, 2010, 114, 6426-6432.

43 N. Soin, S. S. Roy, S. Roy, K. S. Hazra, D. S. Misra, T. H. Lim, C. J. Hetherington and J. A. McLaughlin, J. Phys. Chem. C, 2011, 115(13), 5366-5372.

44 N. Soin, S. S. Roy, C. O'Kane, J. A. McLaughlin, T. H. Lim and C. J. Hetherington, CrystEngComm, 2011, 13(1), 312-318.

45 W. Li, H. Yao, K. Yan, G. Zheng, Z. Liang, Y. M. Chiang and Y. Cui, Nat. Commun., 2015, 6, 7436.

46 S. Sharma, M. N. Groves, J. Fennell, N. Soin, S. L. Horswell and C. Malardier-Jugroot, Chem. Mater., 2014, 26(21), 6142-6151.

47 A. Ganguly, S. Sharma, P. Papakonstantinou and J. Hamilton, J. Phys. Chem. C, 2011, 115, 17009-17019.

48 J. W. Kim, J. D. Ocon, D. W. Park and J. Lee, J. Energy Chem., 2012, 22(2), 336-340.

49 B. Li, S. Li, J. Liu, B. Wang and S. Yang, Nano Lett., 2015, 15, 3073-3079.

50 L. Zhang, L. Ji, P. A. Glans, Y. Zhang, J. Zhu and J. Guo, J. Phys. Chem. Phys., 2012, 14, 13670-13675.

51 L. W. Ji, M. M. Rao, H. M. Zheng, L. Zhang, Y. C. Li, W. H. Duan, J. H. Guo, E. J. Cairns and Y. G. Zhang, J. Am. Chem. Soc., 2011, 133, 18522.
52 J. Rong, M. Ge, X. Fang and C. Zhou, Nano Lett., 2013, 14(2), 473-479.

53 J. Z. Wang, L. Lu, M. Choucair, J. A. Stride, X. Xu and H. K. Liu, J. Power Sources, 2011, 196(16), 7030-7034.

54 W. Ni, J. Cheng, X. Li, Q. Guan, G. Qu, Z. Wang and B. Wang, RSC Adv., 2016, 6(11), 9320-9327.

55 C. Barchasz, F. Molton, C. Duboc, J. C. Leprêtre, S. Patoux and F. Alloin, Anal. Chem., 2012, 84(9), 3973-3980.

56 M. Cuisinier, P. E. Cabelguen, S. Evers, G. He, M. Kolbeck, A. Garsuch, T. Bolin, M. Balasubramaniam and L. F. Nazar, J. Phys. Chem. Lett., 2013, 4, 3227-3232.

57 J. Song, T. Xu, M. L. Gordin, P. Zhu, D. Lv, Y. B. Jiang, Y. Chen, Y. Duan and D. Wang, Adv. Funct. Mater., 2014, 24, 1243-1250.

58 S. Rehman, X. Gu, K. Khan, N. Mahmood, W. Yang, X. Huang, S. Guo and Y. Hou, Adv. Energy Mater., 2016, 6(12), 1502518.

59 Y. X. Wang, L. Huang, L. C. Sun, S. Y. Xie, G. L. Xu, S. R. Chen, Y. F. Xu, J. T. Li, S. L. Chou, S. X. Dou and S. G. Sun, J. Mater. Chem., 2012, 22(11), 4744-4750.

60 W. Kong, L. Sun, Y. Wu, K. Jiang, Q. Li, J. Wang and S. Fan, Carbon, 2016, 96, 1053-1059.

61 R. Singhal, S.-H. Chung, A. Manthiram and V. Kalra, J. Mater. Chem. A, 2015, 3, 4530-4538.

62 R. Chen, T. Zhao, J. Lu, F. Wu, L. Li, J. Chen, G. Tan, Y. Ye and K. Amine, Nano Lett., 2013, 13(10), 4642-4649.

63 Z. Li, J. T. Zhang, Y. M. Chen, J. Li and X. W. D. Lou, Nat. Commun., 2015, 6, 8850.

64 G. Li, J. Sun, W. Hou, S. Jiang, Y. Huang and J. Geng, Nat. Commun., 2016, 7, 10601.

65 S. Lu, Y. Chen, X. Wu, Z. Wang and Y. Li, Sci. Rep., 2014, 4, 4629.

66 J. Guo, Y. Xu and C. Wang, Nano Lett., 2011, 11(10), 42884294.

67 L. Qie and A. Manthiram, Adv. Mater., 2015, 27(10), 16941700.

68 Y. Fu, Y.-S. Su and A. Manthiram, Adv. Energy Mater., 2014, 4(1), 1300655.

69 J. G. Werner, S. S. Johnson, V. Vijay and U. Wiesner, Chem. Mater., 2015, 27(9), 3349-3357.

70 S. Choudhury, M. Zeiger, P. Massuti-Ballester, S. Fleischmann, P. Formanek, L. Borchardt and V. Presser, Sustainable Energy Fuels, 2017, 1(1), 84-94. 